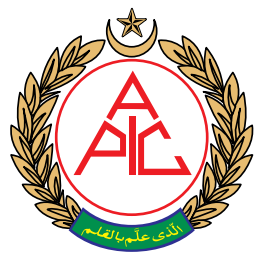

\title{
Comparison of oral pregabalin and intravenous lignocaine for attenuating stress response during intubation in hypertensive patients - A randomized controlled trial
}

\author{
Prasanna Vadhanan, Narendren Ganesh, Revathy Prakash
}

\begin{abstract}
Department of Anesthesiology, Vinayaka Missions Medical College and Hospital, Karaikal- 609609, Pondicherry (Union Territory), (India)

Correspondence:

Dr. Narendren Ganesh

Department of Anesthesiology,

Vinayaka Missions Medical

College and Hospital,

Keezhakasakudimedu,

Kottucherry (P.O), Karaikal609609, Pondicherry (Union Territory), (India).

E-mail: drnarendren2010@gmail.com Phone: +91 9677633144 Received - 14 November 2019;

Reviewed - 25 November

2019, 9, 18 January 2020;

Revised - 19 January 2020;

Accepted - 01 February 2020
\end{abstract}

ABSTRACT

Background: The hemodynamic stress response to intubation needs attenuation in hypertensive individuals. The anesthesiologists have tried various methods and drugs for this purpose. We compared the effectiveness of oral pregabalin and intravenous lignocaine to attenuate the pressor response in patients with stage-1 hypertension in this prospective, randomized double blinded study.

Methodology: Sixty adult patients with diagnosed hypertension, undergoing various elective surgical procedures under general anesthesia, were randomly divided into two groups of 30 each. Group $P$ patients received a single oral dose of pregabalin $150 \mathrm{mg}$ one hour before surgery. Group L patients received lignocaine $1.5 \mathrm{mg} / \mathrm{kg}$ IV before intubation. The hemodynamic changes including baseline heart rate $(\mathrm{HR})$ and blood pressure $(\mathrm{BP})$ were recorded in both groups.

Results: The demographic data, baseline HR and BP, time taken for intubation were similar in both groups. The pregabalin group showed lower post intubation HRs than lignocaine group $(92.07 \pm 10.88$ vs. $98.03 \pm 10.53$ beats $/ \mathrm{min}$ respectively). The mean systolic and diastolic BPs were lower in Group P than in Group L, e.g. $102.33 \pm 13.79 \mathrm{mmHg}$ vs. $120.97 \pm 20.55 \mathrm{mmHg}$ and $62.23 \pm 9.81$ $\mathrm{mmHg}$ vs. $79.23 \pm 16.34 \mathrm{mmHg}$ respectively. The recovery parameters were similar.

Conclusion: Oral pregabalin $150 \mathrm{mg}$ is more effective to minimize pressure response to intubation in patients with stage-1 hypertension when compared to lignocaine $1.5 \mathrm{mg} / \mathrm{kg} \mathrm{IV}$.

Key words: Stress response; Intubation; Pregabalin; Lignocaine; Hypertension

Citation: Vadhanan P, Narendren G, Revathy. Comparison of oral pregabalin and intravenous lignocaine for attenuating stress response during intubation in hypertensive patients $-\mathrm{A}$ randomized controlled trial. Anaesth. pain intensive care 2020;24(1): 225-229

DOI: https://doi.org/10.35975/apic.v24i1.1259

\section{INTRODUCTION}

Endotracheal intubation is an essential skill which should be mastered by every anesthesiologist. Stimulation of sensory receptors of the airway during laryngoscopy and intubation activates sympathetic system, releases catecholamines causing deleterious effects like tachycardia, hypertension, increasing oxygen demand and increase in intracranial, intraocular pressures. This is called the pressor response. Intubation is perhaps a stronger stimulus than laryngoscopy which may be more noxious than a surgical incision. The isolated forearm response, an indicator for 
awareness was positive in $46 \%$ and $41 \%$ patients during intubation and laryngoscopy respectively but only in $23 \%$ during skin incision. ${ }^{1}$

Patients with systemic hypertension generally exhibit exaggerated response during laryngoscopy and intubation. ${ }^{2,3}$ Stress response is usually transient and is well tolerated in healthy individuals without any significant effects. But in certain population with comorbid conditions like coronary artery disease and hypertension the response can result in adverse events like myocardial infarction and arrhythmias. Abolition of stress response is of paramount importance in these individuals.

Some of the methods by which the stress response can be minimized are by using judicious premedication, performing intubation in a deeper plane, gentle laryngoscopy, avoiding laryngeal manipulation and with drugs like beta blockers, opioids, calcium channel blockers, vasodilators and alpha agonists just before intubation. Among the pharmacological methods lignocaine is the widely used drug. Gabapentinoids, derivatives of gamma amino butyric acid (GABA ) have been primarily used for neuropathic pain, ${ }^{4}$ as well as various off label indications. ${ }^{5,6,7}$ Pregabalin is a structural analogue of gabapentin with an additional advantage of having bioavailability of $90 \%$ compared to $60 \%$ of gabapentin. ${ }^{8}$ After oral administration peak levels are achieved within one hour. Few studies have been conducted evaluating the efficacy of pregabalin in attenuating stress response to intubation. ${ }^{9}$. We aimed to compare oral pregabalin to intravenous lignocaine in attenuating the hemodynamic response during laryngoscopy and intubation in patients with stage-1 hypertension. (systolic BP 130-139 $\mathrm{mmHg}$ and diastolic BP $80-89 \mathrm{mmHg}$ ), according to 2017 ACC/AHA guidelines. ${ }^{11}$

\section{METHODOLOGY}

The trial was designed as a prospective randomized double-blind study in a teaching hospital. Ethics committee approval was obtained from institutional ethics committee, and the trial was registered with the Srilankan
Clinical Trial Registry (SLCTR2018/032). Patients with stage-1 hypertension, who were posted for various elective surgeries under general anesthesia, were recruited for the study. Informed written consent was obtained. Exclusion criteria were; anticipated difficult airway, any other comorbid conditions like cardiac, hepatic, neurologic or endocrine disorders and pregnancy. The sample size was calculated based on an anticipated $10 \%$ change from baseline values, a power of $80 \%$ and significance level of $5 \%$ which was similar to previous studies done upon pressure attenuation. $^{12}$

Randomization was done by using computer generated random tables (generated by Random Allocation software, $v$ 1.0.0) into two groups in blocks of five: Group P (pregabalin), and Group L (lignocaine), each group consisting of 30 patients. Sealed opaque envelopes were used to conceal randomization. The patients were kept fasting $8 \mathrm{~h}$ prior to surgery. All patients were given diazepam $5 \mathrm{mg}$, ranitidine $150 \mathrm{mg}$ and ondansetron $4 \mathrm{mg}$ PO the night prior to surgery. All the patients were asked to continue their respective antihypertensive drugs till the morning of surgery. Group $\mathrm{P}$ patients received pregabalin $150 \mathrm{mg} \mathrm{PO}$ one hour before anesthesia induction in the holding area to achieve a maximum therapeutic concentration during induction. Group L patients received similar looking placebo capsules. Both the patient and the provider administering the drugs were blinded to the group allocation.

Patients were shifted to operating room, basic monitors were attached - pulse oximeter, noninvasive BP, electrocardiography and capnography (after intubation). Patients were secured with $18 \mathrm{G}$ intravenous cannula and started on Ringer lactate infusion. Baseline vital signs were recorded. Patients were preoxygenated with $100 \%$ oxygen for $3 \mathrm{~min}$. All the patients then received midazolam 0.02 $\mathrm{mg} / \mathrm{kg}$, glycopyrrolate $0.2 \mathrm{mg}$ and butorphanol $0.04 \mathrm{mg} / \mathrm{kg}$ IV. Group $\mathrm{P}$ patients received normal saline injection $3 \mathrm{ml}$ and Group L patients received $1.5 \mathrm{ml} / \mathrm{kg}$ of preservative free lignocaine intravenously. The patient and the 
anesthesiologists administering the drugs, performing the intubation, and monitoring the parameters were blinded to the group allocation. Patients were induced with propofol $2 \mathrm{mg} / \mathrm{kg}$ IV. After attaining mask ventilation, muscle relaxation was achieved with vecuronium 0.1 $\mathrm{mg} / \mathrm{kg}$ body weight and were ventilated for 3 min with a mixture of 50:50 oxygen, nitrous oxide and sevoflurane $2 \%$. All patients were intubated by the same consultant anesthesiologist with over $10 \mathrm{y}$ of experience using standard techniques. If time taken for intubation (defined as time from discontinuation of mask ventilation to passage of endotracheal tube through the glottis) exceeded $30 \mathrm{sec}$, patients were again mask ventilated, plane deepened with propofol $0.5 \mathrm{mg} / \mathrm{Kg} \mathrm{IV}$ and procedure repeated. Heart rate (HR), systolic, diastolic and mean arterial $\mathrm{BP}$ were recorded at the following time intervals - baseline, just before intubation, $1 \mathrm{~min}, 3 \mathrm{~min}$ and $5 \mathrm{~min}$ after intubation, then every $5 \mathrm{~min}$ till $30 \mathrm{~min}$.. Number of attempts of intubation and other

maneuvers used e.g. bougie and OELM (optimal external laryngeal manipulation), were also noted. Anesthesia was maintained with $30 \% \quad \mathrm{O}_{2}+70 \% \quad \mathrm{~N}_{2} \mathrm{O}+1-2 \%$ sevoflurane. After completion of the surgery patients were reversed with neostigmine $0.05 \mathrm{mg} / \mathrm{kg}$ and glycopyrrolate $0.01 \mathrm{mg} / \mathrm{kg}$ and the patients extubated.

Following interventions were performed where indicated within the study period. A pulse rate $<50$ beats/min was considered as bradycardia and was corrected with atropine $0.02 \mathrm{mg} / \mathrm{kg}$ IV. Pulse rate over $100 / \mathrm{min}$ or a $20 \%$ increase from baseline was considered tachycardia corrected by esmolol $0.5 \mathrm{mg} / \mathrm{kg}$. Any event of fall in BP to less than $20 \%$ of baseline was corrected with mephentermine $6 \mathrm{mg}$ bolus. $\mathrm{BP} \geq 20 \%$ from baseline was
Table 1: Demography and intubation parameters

\begin{tabular}{lccc}
\multicolumn{1}{c}{ Parameter } & Group P & Group L & p-value \\
\hline Age (Years, mean \pm SD) & $39.13 \pm 11.63$ & $42.03 \pm 11.41$ & 0.334 \\
\hline Male / Female & $10 / 20$ & $7 / 23$ & 0.39 \\
\hline Mallampati (1/2/3/4) & $4 / 22 / 4 / 0$ & $0 / 28 / 2 / 0$ & 0.068 \\
\hline $\begin{array}{l}\text { Intubation time (Sec, mean } \pm \\
\text { SD) }\end{array}$ & $30.67 \pm 2.54$ & $27.22 \pm 9.42$ & 0.11 \\
\hline Intubation attempts (1st/2nd) & $29 / 1$ & $29 / 1$ & 1 \\
\hline Bougie or OELM & 1 & 2 & 0.5
\end{tabular}

corrected with inj esmolol $0.5 \mathrm{mg} / \mathrm{kg}$ IV. Side effects like nausea, vomiting, giddiness or a delayed recovery in the postoperative period were also noted.

\section{Statistical analysis:}

Statistical analysis was done using Microsoft excel 2016 with Realstatistics package installed. Continuous data was checked for normalcy using Shapiro-Wilk test and by analyzing skewness and kurtosis. Student's t test was used if the data was normally distributed. For categorical data Chi- squared test and Fisher's Exact test for smaller values (less than 5) were used. A p $<0.05$ is considered significant.

\section{RESULTS}

All sixty patients screened fulfilled the inclusion criteria. They were randomized into groups of 30 each. All patients were followed up and analyzed. Demographic parameters in both groups were comparable (Table 1). The mean age was comparable in two groups $(\mathrm{p}=0.33)$. The anti-hypertensive medications used by the patients are shown in Table 2. The comparison of intubation parameters in both the groups also didn't show much variation.

The Mallampatti grades, used as a predictor for difficult airway were similar in both the groups $(\mathrm{p}=0.068)$. The intubation time was comparable $(\mathrm{p}=0.109)$. All except one patient in each group were intubated in the first attempt.

One patient in Group $\mathrm{P}$ and two patients in Group L required bougie for intubation due to difficulties encountered in guiding the tube through the glottis $(p=0.55)$. All the three 
Table 2: Anti-hypertensive medications

\begin{tabular}{lcc}
\multicolumn{1}{c}{ Drug therapy } & $\begin{array}{c}\text { Group P } \\
\text { (Pregabalin) }\end{array}$ & $\begin{array}{c}\text { Group L } \\
\text { (Lignocaine) }\end{array}$ \\
\hline Diuretics & 20 & 19 \\
\hline ARB $^{*}$ or ACEi & \\
\hline Diuretics plus ARB/ACEi & 9 & 7 \\
\hline Calcium channel blockers & 1 & Nil \\
\hline No medications/ alternate systems & Nil & 3 \\
\hline
\end{tabular}

*OELM - Optimal external laryngeal manipulation; *ARB - Angiotensin receptor Blocker, ${ }^{\dagger} A C E i-A n g i o t e n s i n$ converting enzyme inhibitor

Table 4: Comparative SBP at different times (mmHg)

\begin{tabular}{lccc}
\multicolumn{1}{c}{ Time } & $\begin{array}{c}\text { Group P } \\
\text { (Pregabalin) }\end{array}$ & $\begin{array}{c}\text { Group L } \\
\text { (Lignocaine) }\end{array}$ & p-value \\
\hline Base line & $133.27 \pm 28.43$ & $137.0 \pm 15.10$ & 0.527 \\
\hline Zero min & $97.30 \pm 14.24$ & $100.43 \pm 11.88$ & 0.358 \\
\hline 1 min post-intubation & $102.33 \pm 13.79$ & $120.97 \pm 20.55$ & $<\mathbf{0 . 0 0 1}$ \\
\hline 3 min post-intubation & $105.43 \pm 14.11$ & $111.17 \pm 20.14$ & 0.207 \\
\hline 5 min post-intubation & $107.80 \pm 12.44$ & $107.30 \pm 18.65$ & 0.903
\end{tabular}

Table 3: Comparative HRs at different times (Beats/min)

\begin{tabular}{llcc}
\multicolumn{1}{c}{ Time } & $\begin{array}{c}\text { Group P } \\
\text { (Pregabalin) }\end{array}$ & $\begin{array}{c}\text { Group L } \\
\text { (Lignocaine) }\end{array}$ & p value \\
\hline Base line & $87.93 \pm 15.17$ & $88.1 \pm 14.20$ & 0.854 \\
\hline Zero min & $86.10 \pm 12.21$ & $88.6 \pm 10.02$ & 0.389 \\
\hline 1 min post-intubation & $92.07 \pm 10.88$ & $98.03 \pm 10.53$ & $\mathbf{0 . 0 3 5}$ \\
\hline 3 min post-intubation & $94.43 \pm 14.68$ & $92.97 \pm 11.03$ & 0.663 \\
\hline 5 min post-intubation & $87.03 \pm 13.97$ & $87.20 \pm 9.69$ & 0.957
\end{tabular}

was $88.1 \pm 14.20$ and $88.6 \pm 10.02$ beats $/ \mathrm{min}$ respectively which were comparable $(\mathrm{p}=0.8$, Table 3). But post intubation value after 1 min in Group P was $92.07 \pm 10.88$ beats/min and in Group L was $98.03 \pm 10.53$ beats/min which was significant ( $\mathrm{p}$ value 0.03). But post intubation values after $3 \mathrm{~min}$ and 5 min were not significant. patients had a

Cormack-Lehane score of 3.Baseline HR in beats/min and just before intubation (zero min) in Group P was $87.93 \pm 15.17$ and $86.10 \pm 12.21$ beats/min and Group L Baseline and preintubation systolic BP (Table 4) in Group P was $133.27 \pm 28.43$ and $97.30 \pm 14.24$ $\mathrm{mmHg}$ and Group L was $137.0 \pm 15.10$ and $100.43 \pm 11.88 \mathrm{mmHg}$ which was not significant ( $\mathrm{p}$ value 0.527

0.527 respectively). Systolic BP 1 min after intubation in Group P was $102.33 \pm 13.79$ $\mathrm{mmHg}$ and in Group L was $120.97 \pm 20.55$ $\mathrm{mmHg}$ and which was very significant $(\mathrm{p}<$ 0.001). Post intubation values at $3 \mathrm{~min}$ and 5 min in both groups were not significant.

Comparative data of diastolic BP is given in Table 5. It shows that baseline and preintubation diastolic BP in Group P was 86.10 \pm 10.03 and $58.83 \pm 9.12 \mathrm{mmHg}$ respectively and in Group L was $84.77 \pm 11.35$ and $61.30 \pm$ $11.69 \mathrm{mmHg}$ which was not significant $(\mathrm{p}=$ 0.63 and 0.36 respectively). Diastolic BP in and in Group $\mathrm{P}$ was $62.23 \pm 9.81 \mathrm{mmHg}$ and in Group L was $79.23 \pm 16.34 \mathrm{mmHg}$ after $1 \mathrm{~min}$ of intubation, and difference was very significant $(\mathrm{p}<0.001)$. Post intubation values at $3 \mathrm{~min}$ and $5 \mathrm{~min}$ in both groups were not 
Table 5: Comparative DBP at different times ( $\mathrm{mmHg}$ )

\begin{tabular}{llll}
\multicolumn{1}{c}{ Time } & $\begin{array}{c}\text { Group P } \\
\text { (Pregabalin) }\end{array}$ & $\begin{array}{c}\text { Group L } \\
\text { (Lignocaine) }\end{array}$ & p-value \\
\hline Base line & $86.10 \pm 10.03$ & $84.77 \pm 11.35$ & 0.631 \\
\hline Zero min & $58.83 \pm 9.12$ & $61.30 \pm 11.69$ & 0.366 \\
\hline 1 min post-intubation & $62.23 \pm 9.81$ & $79.23 \pm 16.34$ & $<0.001$ \\
\hline 3 min post-intubation & $63.97 \pm 10.32$ & $72.43 \pm 22.29$ & 0.064 \\
\hline 5 min post-intubation & $65.10 \pm 9.31$ & $67.20 \pm 13.99$ & 0.497
\end{tabular}

pressure
attenuation, ${ }^{14,15}$ and

still fewer have compared pregabalin with lignocaine - one of the widely used drugs for stress response attenuation. In a similar study done on 'controlled hypertensive' patients, Meena et al ${ }^{16}$ have concluded that a dose of $300 \mathrm{mg}$

significant $(p=0.06$ and 0.49$)$. None of the patients had delayed recovery or undue sedation during the study period. None of the patients required any additional drugs for hemodynamic fluctuations.

\section{DISCUSSION}

Hypertensive patients develop variety of adverse cardiovascular events during or immediately after endotracheal intubation. A higher rate-pressure product immediately before tracheal intubation has been associated with significant increase, and may result in myocardial ischemia after or during intubation. ${ }^{13}$ Various drugs have been used to minimize stress response during intubation. Most drugs act on the autonomic system and decreases the HR, BP and sometimes myocardial contractility. The decrease in cardiac output may not be desirable in all patients. Pregabalin with its different action on voltage gated calcium channels decreases the release of excitatory neurotransmitters. The anti-anxiety and analgesic action might be useful in the perioperative period. In our study all patients demonstrated effective hemodynamic attenuation in terms of HR and BP with significantly lower HR values at $1 \mathrm{~min}$ after intubation. $(\mathrm{p}=0.035)$. Similarly, the systolic and diastolic BP were also lower in the pregabalin group than the lignocaine group at 1min post intubation, which was highly significant $(\mathrm{p}<0.001)$. Few studies have compared oral pregabalin with placebo for pregabalin produced better pressure attenuation than $150 \mathrm{mg}$. However, the authors have not defined controlled hypertension and degree of sedation was significantly higher preoperatively in the $300 \mathrm{mg}$ group, which may not be always desirable. A dose of $150 \mathrm{mg}$ pregabalin has been shown to produce better pressure attenuation than $75 \mathrm{mg} .{ }^{17}$

Various factors can influence the degree of stress response to intubation - baseline parameters, smoothness of intubation or the lack of it, plane of anesthesia to name a few. All these parameters are accounted for and were comparable in both groups. The HR at one min after intubation was significantly lower in the pregabalin group as compared to lignocaine. Lignocaine has been shown to produce lesser decreases in HR when compared to fentanyl when used for pressure attenuation. ${ }^{18}$ Similarly, the systolic, diastolic and mean BP were significantly lower in pregabalin group at $1 \mathrm{~min}$ after intubation when compared to lignocaine. Our results agree with the study done by Eren et al where $150 \mathrm{mg}$ pregabalin produced effective pressure attenuation than placebo in normotensive individuals. ${ }^{15}$ In contrast, in a study comparing pregabalin and lignocaine in normotensive patients, Talikoti et al, concluded that lignocaine achieved lesser increases in HR and systolic pressures but pregabalin controlled the diastolic pressure better. ${ }^{19}$ Our study group included hypertensive individuals, who were on various antihypertensive drugs which might be the response for the discrepancy. Diuretics, angiotensin receptor blockers, beta blockers, 
calcium channel blockers are the commonly used drugs to treat hypertension. These drugs reduce $\mathrm{BP}$ by different mechanisms and have varied effects on the HR. This might explain the discrepancy in HR and pressure attenuation among the study drugs. Pressure attenuation technique acts upon the airway receptors, central nervous system or the peripheral autonomic system. While lignocaine produces a direct myocardial depressant effect, a peripheral vasodilating effect and finally an effect on synaptic transmission, ${ }^{20}$ pregabalin predominantly acts in the central nervous system diminishing the sympathetic outflow and hence blocks the response at a more central site when compared to beta blockers. Pregabalin treatment has been shown to cause lower exercise induced HR, BP and perceived exertion in fibromyalgia patients, indicating a beneficial hemodynamic profile during stress. $^{21}$ Lignocaine can potentiate neuromuscular blockade and delay recovery, whereas the sedative effects of pregabalin might cause the same. None of our patients had delayed recovery.

The strengths of the study are inclusion of patients with hypertension, standardization of intubation procedure and rigorous statistical analysis.

\section{LIMITATIONS}

Some of the limitations of our study include our inability to standardize the anti-hypertensive medications and duration of hypertension (which varied from recently diagnosed to more than 1 year) among the study groups, small sample size and inclusion of only stage- 1 hypertension. The results may not be valid to patients with higher and uncontrolled BP and older age groups. Even though numerous studies evaluating pregabalin for pressure attenuation exist, they suffer from lack of standardization, uniformity of patient profile and varied control groups to name a few. A systematic review and meta-analysis of available studies would enable us to use the drug routinely in clinical practice. Further studies evaluating the drug in more severe hypertensive patients are warranted.

\section{CONCLUSION}

Oral pregabalin $150 \mathrm{mg}$ is more effective to minimize pressure response to intubation in patients with stage-1 hypertension when compared to lignocaine $1.5 \mathrm{mg} / \mathrm{kg}$ IV.

In conclusion pregabalin $150 \mathrm{mg} \mathrm{PO}$ and lignocaine $1.5 \mathrm{mg} / \mathrm{kg} \mathrm{IV}$, both can be used to attenuate pressor response during intubation in patients with stage-1 hypertension, but pregabalin is comparatively more effective in this regard.

Conflict of interest: None declared by the authors. Authors' contribution:

PV - Concept, supervision, manuscript preparation NG - Study design, data analysis, literature search RP - Data collection, resource management, implementation

\section{REFERENCES}

1 Zand F, Hadavi SMR, Chohedri A, Sabetian $P$. Survey on the adequacy of depth of anaesthesia with bispectral index and isolated forearm technique in elective Caesarean section under general anaesthesia with sevoflurane. $\mathrm{Br} \mathrm{J}$ Anaesth 2014 Feb 13;112(5):871-8. [PubMed] DOI: 10.1093/bja/aet483.

2. Nishikawa K, Omote K, Kawana S, Namiki A. A comparison of hemodynamic changes after endotracheal intubation by using the lightwand device and the laryngoscope in normotensive and hypertensive patients. Anesth Analg $2000 \quad$ May;90(5):1203-7. [PubMed] DOI: $10.1097 / 00000539-$ 200005000-00038

3. Low JM, Harvey JT, Prys-Roberts C, Dagnino J. Studies of anaesthesia in relation to hypertension. VII: Adrenergic responses to laryngoscopy. $\mathrm{Br} \mathrm{J}$ Anaesth 1986 May;58(5):471-7. [PubMed]

4. Tremont-Lukats IW, Megeff C, Backonja MM. Anticonvulsants for neuropathic pain syndromes: mechanisms of action and place in therapy. Clin J Pain 2000;16(2):1029-52. [PubMed] DOI: $\quad 10.2165 / 00003495-$ 200060050-00005

5. Goodman CW, Brett AS. A Clinical Overview of Off-label Use of Gabapentinoid Drugs. JAMA Intern Med. 2019;179(5):695-701. [PubMed] DOI: 10.1001/jamainternmed.2019.0086

6. Ban VS, Bhoja R, McDonagh DL. Multimodal analgesia for craniotomy. Curr Opin Anaesthesiol. $2019 ; 32(5): 592-599 . \quad$ [PubMed] 
DOI:

10.1097/ACO.0000000000000766

7. Rascón-Martínez DM, GuzmánSánchez JA, Corral-Urdapilleta NP, Arguelles-Uribe GD, VelázquezLoeza J, Soto-Palma G, et al. Gabapentine $300 \mathrm{mg}$ vs. $450 \mathrm{mg}$ as anesthetic premedication for reactive hypertension, anxiety and analgesia. Gac Med Mex 2018;154(1):54-61. [PubMed] [Free Full Text] DOl: 10.24875/GMM.17002796.

8. Stewart B, Kugler A, Thompson P, Bockbrader $\mathrm{H}$. A saturable transport mechanism in the intestinal absorption of gabapentin is the underlying cause of the lack of proportionality between increasing dose and drug levels in plasma. Pharm Res. 1993;10(2):276-81. [PubMed]

9. Gupta K, Bansal P, Gupta PK, Singh YP. Pregabalin premedication - A new treatment option for hemodynamic stability during general anaesthesia A prospective study. Anesth Essays Res. 2011;5(1):57-62. [PubMed] [Free Full Text] DOI: 10.4103/02591162.84192.

10. Waikar C, Singh J, Gupta D, Agrawal A. Comparative Study of Oral Gabapentin, Pregabalin, and Clonidine as Premedication for Anxiolysis, Sedation, and Attenuation of Pressor Response to Endotracheal Intubation. Anesth Essays Res 2017;11(3):558-560. [PubMed] [Free Full Text] DOl: 10.4103/aer.AER 3417.

11. Whelton PK, Carey RM, Aronow WS, Casey DE, Collins KJ, Himmelfarb CD, et al. 2017 ACC/AHA/AAPA/ABC/ACPM/AGS/ APhA/ASH/ASPC/NMA/PCNA Guideline for the Prevention, Detection, Evaluation, and Management of High Blood
Pressure in Adults: Executive Summary: A Report of the American College of Cardiology/American Heart Association Task Force on Clinical Practice Guidelines. Hypertension 2018;71(6):1269-324. [PubMed] [Free Full Text] DOI: 10.1161/HYP.0000000000000066.

12. Sulaiman $\mathrm{S}$, Karthekeyan $\mathrm{RB}$, Vakamudi K, Sundar AS, Ravullapalli H, Gandham R. The effects of dexmedetomidine on attenuation of stress response to endotracheal intubation in patients undergoing elective off-pump coronary artery bypass grafting. Ann Card Anaesth. 2012;15:39-43. [PubMed] DOI: 10.4103/09719784.91480

13. Edwards ND, Alford AM, Dobson PMS, Peacock JE, Reilly CS. Myocardial ischaemia during tracheal intubation and extubation. Br J Anaesth. 1994; Oct;73(4):5379. [PubMed]

14. Singh D, Yadav JS, Jamuda BK, Singh $P$. Oral pregabalin as premedication on anxiolysis and stress response to laryngoscopy and endotracheal intubation in patients undergoing laparoscopic cholecystectomy: A randomized double-blind study. Anesth Essays Res. 2019;13:97-104. [PubMed] [Free Full Text] DOI: 10.4103/aer.AER_12_19

15. Eren G, Kozanhan B, Hergunsel O, Bilgin U, Demir G, et al. Pregabalin blunts cardiovascular response to laryngoscopy and tracheal intubation. J Anesthesiol Reanimation. 2008;7:82-87.

16. Meena R, Meena K, Prakash S . Study of Attenuation of Cardiovascular Response during Laryngoscopy and Intubation Using Two Different Doses of Pregabalin as Premedication in Controlled Hypertensive Patients-A RCT. J
Anesth Clin Res. 2016;7:607. [Free Full Text] DOI: 10.4172/21556148.1000607

17. Rastogi R, Gupta K, Gupta PK, Agarwal $S$, Jain $M$, Chauhan $H$. Oral pregabalin premedication for attenuation of hemodynamic response of airway instrumentation during general anaesthesia: $A$ dose response study. Ind $\mathrm{J}$ Anaesth 2012;56(1):49-54. [PubMed] [Free Full Text] DOI: 10.4103/00195049.93344 .

18. Thippeswamy RR, Shetty SR. Intravenous low dose fentanyl versus lignocaine in attenuating the hemodynamic responses during endotracheal intubation: A randomized double-blind study. Anesth Essays Res. 2018;12:77885. [PubMed] [Free Full Text] DOI: 10.4103/aer.AER_111_18

19. Talikoti AT, Dinesh K, Deepak VD, Nanda A, Somasekharam $P$. Comparison of injection lignocaine (preservative free) $1.5 \mathrm{mg} / \mathrm{kg}$ i.v with oral pregabalin $150 \mathrm{mg}$ for attenuation haemodynamic response to laryngoscopy and tracheal intubation. J Indian Med Assoc. 2013 Oct;111(10):692-6. [PubMed]

20. Yukioka H, Yoshimoto N, Nishimura K, Fujimori M. Intravenous lidocaine as a suppressant of coughing during tracheal intubation. Anesth Analg. 1985 Dec; 64(12):1189-92 [PubMed]

21. White AT, Light KC, Bateman L, Hughen RW, Vanhaitsma TA, Light AR. Effect of pregabalin on cardiovascular responses to exercise and post esercise pain and fatigue in fibromyalgia: A randomized double-blind cross over pilot study. Pain Res Treat. 2015; 2015: 136409. [PubMed] [Free Full Text] DOI: $\underline{10.1155 / 2015 / 136409}$. 